\title{
Dose Rate Influence on Deep Dose Deposition Using a 6 MV X-Ray Beam From a Linear Accelerator
}

\author{
R.V. Sousa* \\ Departamento de Química, Instituto de Ciências Exatas, \\ Universidade Federal de Minas Gerais, Av. Antônio Carlos, \\ 6627, Pampulha, Belo Horizonte, MG, CEP 31270-901, Brasil
}

(Received on 20 January, 2009)

\begin{abstract}
Linear accelerators used in radiation therapy treatments usually provide the capability of irradiating with different dose rates. The medical physicist may choose arbitrary the dose rate to use, although the relative biological effectiveness (RBE) varies with this physical parameter. In this work the measurements of absorbed dose of the x-ray beams from a Varian $6 \mathrm{MV}$ linear accelerator CLINAC 600C/D were made in a water phantom, using an appropriate dosimetry system, consisting of an electrometer and a waterproof ionization chamber. The code of practice for dosimetry used in this work is the IAEA (International Atomic Energy Agency) TRS-398, since water relates closely to the biological effects of radiation. The measurements were made in three depths, with three different field sizes and six different dose rates. The data were treated and the graphs show the obtained results. Different dose rates changes the deep dose deposition at the same depth and this must be considered in the planning.
\end{abstract}

Keywords: dose rate, x-ray beam, dosimetry, deep dose deposition.

Introduction

According to World Health Organization, cancer causes around 7.9 million deaths worldwide each year. The main therapies for this disease are oncologic surgery, chemical therapy and radiation therapy. The radiation therapy is indicated around $50 \%$ of the cancer patients. The main radiation therapy modality is teletherapy - the radiation source is placed outside the body and the emitted beam penetrates the tissues, interacting with normal and tumor cells. Various radiation emitter equipments to treat cancer can be used - for deep tissues the main is the linear accelerator (LINAC). In a LINAC accelerated electrons collide with a target right after pass through a linear tube where they get more energy. After this interaction the bremsstrahlung X-ray beam exits the machine head, interacting with the patient tissues.

Various LINACs used in Radiation Therapy Centers provide the capability of irradiating patients with several different dose rates $\left(\mathrm{cGy} \cdot \mathrm{min}^{-1}\right)$. This physical parameter has to be considered because different dose rates may change the collection efficiency of the monitor ionization chambers (IC) localized at the LINAC head, as well as the relative biological effectiveness (RBE) [1]. The calibration of the monitor ionization chamber of a LINAC should be determined at all available dose rates $[2,3]$. Usually the medical physicist chooses arbitrarily the dose rate to use in most treatments.

In this paper the effect of changing the dose rate of the $\mathrm{x}$-ray beam of a Varian CLINAC 600C/D is analyzed. The radiation dose is measured in an official dosimetry system calibrated at a Secondary Standard Dosimetry Laboratory. The results are showed and discussed.

\footnotetext{
*Electronic address: romuloverdolin@yahoo.com.br
}

The Importance Of The Dose Rate

The biological effects of radiation therapy depend on several factors like dose distribution, treated volume, dose rate, treatment duration, patient health conditions and other ones.

The influence of radiation quality is limited for sparsely ionizing radiation but the influence of dose rate cannot be ignored at all. Radiobiological data from animal and cells experiments indicate a sparing effect when the dose rate is reduced [4]. For the same dose, radiation delivered at a lower dose rate may produce less killing than radiation delivered at a higher dose rate because sub lethal damage repair occurs during the protracted exposure [2].

At some specific cases, like IMRT (Intensity Modulated Radiation Therapy), the high dose rate is desirable for reducing the treatment time because it is considered the organ movement. Teh Lin et. al studied the averaged delivered dose at three different positions for 100, 500 and 1000 MU.min ${ }^{-1}$ (monitor units/minute) dose rates at phantom static and phantom moving with $30 \%-60 \%$ gating window cases. They concluded that the differences in measured dose between different dose rates are about $1 \%$ and the dose rate does not seem to have a significant effect on gated IMRT dose delivery [5].

\section{The CLINAC 6 MV}

The CLINAC 600C/D is a LINAC used in radio therapeutic treatment of diseases, like malignant tumor (cancer). This machine generates a $6 \mathrm{MV}$ x-ray beam, with rectangular symmetric and asymmetric fields. It can be used stationary therapy and arc therapy. There is an integrated control system that simplifies the operation and monitors the performance of the equipment. The major components are: operator console, console electronics cabinet, drive stand, gantry and treatment couch.

The x-ray beam consists of a series of pulses occurring at a frequency of up to 405 pulses per second. The electrons are injected into the LINAC by an electron gun. A high power microwave magnetron produces a RF pulse that accelerates the 
electrons. The electrons are introduced into the linear tube as bunches. These electrons bunches pass through succeeding cavities into the linear tube with accelerating electric fields and their mass and kinetic energy increase. The high energy electrons produced by the system are directed at a metal target, producing a heterogeneous bremsstrahlung $\mathrm{x}$-ray beam of up to $6 \mathrm{MV}$.

The dose rate for stationary therapy on the CLINAC $600 \mathrm{C} / \mathrm{D}$ is variable in six equal increments from 100 MU.min ${ }^{-1}$ up to 600 MU.min ${ }^{-1}$ [6]. Typically 1 MU corresponds to a dose of $1 \mathrm{cGy}$ delivered in a water phantom at the depth of maximum dose on the central axis beam when irradiated with a $(10 \times 10) \mathrm{cm}^{2}$ field at a source-surface distance of $100.0 \mathrm{~cm}$.

The treatment time is calculated using the MU value, the current dose rate value and a multiplication factor configured by the hospital. If the user changes the dose rate after the time is set there may be adverse effects on the use of time as a safety factor: [7]

- If the dose rate is increased, the equipment fails to terminate the beam when the set dose is delivered; so a larger overdose is delivered before a time interlock cuts off the beam;

- If the dose rate is decreased, the treatment is more likely to terminate with a time interlock before the set dose is completely delivered.

In both cases the user has to modify the parameters before expose the patient to the $\mathrm{x}$-ray beam, configuring the console computer that controls the LINAC.

Interlock circuits are provided throughout the CLINAC to protect people and equipment from unsafe conditions that may arise in subsystems of the equipment during its operation [6]. There are three kinds of C-Series interlocks: major, minor and dosimetry:

- The major interlocks identify conditions that could damage the equipment, like restricted cooling water flow and accelerator vacuum loss;

- The minor interlocks alert the operator to the existence of conditions that affect machine operation, like treatment room door open and filament time delay;

- The dosimetry interlocks identify conditions in which the ability of the equipment to deliver or measure dose may be impaired, like calibration cycle timeout and excess dose rate.

The dose rate control is made by modulating the gun pulses which fall in coincidence with the RF pulses to the guide [6]. The console computer sends a set repetition rate command corresponding to the dose rate selected by the operator to the control processor. The electron gun works with a delaying of a fixed number of times out of a set sequence of pulses, corresponding to the chosen value. There are three dose rate dosimetry interlocks:

- XDR1 (system delivered a radial dose rate in excess of $150 \%$ of the set dose rate);
- XDR2 (system delivered a transverse dose rate in excess of $150 \%$ of the set dose rate);

- XDRS (the actual servoed dose rate over time is above the intended dose rate).

\section{The Dosimetry System}

The correct determination of absorbed dose in patient tissues is very important. The International Commission on Radiation Units and Measurements (ICRU) suggests that the uncertainty on dose measurement must be $\pm 5 \%$ [8]. Modern radiotherapy shows the need for high accuracy in dose delivery, especially when advanced techniques are used.

The absorbed dose to water is the main quantity used in radiation therapy since this one relates closely to the biological effects of radiation [9]. The advantages obtained from the use of water include reduced uncertainty, a more robust system of primary standards and the use of a simple formalism [8]. The IAEA TRS-398 developed by International Atomic Energy Agency can be used with most radiation types and ranges of beam qualities, including high-energy photons generated by electrons with energies varying from 1 to $50 \mathrm{MeV}$.

We can determine the absolute value of absorbed dose to water with three basic methods: calorimetry, chemical dosimetry and ionization dosimetry:

- Calorimetry involves the use of a calorimeter, a device that measures the heat in various processes;

- Chemical dosimetry involves the determination of dose by the measurement of chemical changes induced by ionizing radiation;

- Ionization dosimetry involves the use of an IC, a device that can be used for detecting particles and for detection or measurement of ionizing radiation.

In this work it was used an IC which consists of a graphite cavity chamber with accurately known chamber volume fulfilled with a gas.

The absorbed dose to water at the reference depth $z_{\text {ref }}$ in water for a reference beam of quality $Q_{0}$ and in the absence of the chamber is given by [8]:

$$
D_{W Q_{0}}=M_{Q_{0}} \times N_{D, w, Q_{0}}
$$

In equation (1) $M_{Q_{0}}$ is the reading of the dosimeter under the reference conditions in the standard laboratory and $N_{D, W, Q_{0}}$ is the calibration factor in terms of absorbed dose to water of the dosimeter obtained from a standard laboratory. In practice the measurement conditions do not match the reference conditions used in the standard laboratory and this may affect the response of the dosimeter. Some factors are used to correct this problem.

Reference conditions are a set of values of influence quantities for which the calibration factor is valid without corrections. These conditions include distance, depth, field size, temperature, pressure and relative air humidity.

When a dosimeter is used in different conditions than the reference ones, the absorbed dose to water is given by [8]:

$$
D_{W, Q_{0}}=M_{Q} \times N_{D, w, Q_{0}} \times k_{Q, Q_{0}}
$$


In equation (2) the factor $k_{Q, Q_{0}}$ corrects for the effects of the difference between the reference beam quality $Q_{0}$ and the actual user quality $Q$. The dosimeter reading $M_{Q}$ has been corrected to the reference values of influence quantities other than beam quality, for which the calibration factor is valid. The beam quality correction factor $k_{Q, Q_{0}}$ is defined as the ratio of the calibration factors in terms of absorbed dose to water of the IC [8]:

$$
k_{Q, Q_{0}}=\frac{N_{D, w, Q}}{N_{D, w, Q_{0}}}=\frac{D_{w, Q} / M_{Q}}{D_{w, Q_{0}} / M Q_{0}}
$$

The ${ }^{60} \mathrm{Co}$ is the most common reference quality $Q_{0}$ used for calibration of IC worldwide. The reference conditions are described in Table 1.

Table 1. Reference conditions

\begin{tabular}{|c|c|}
\hline Influence quantity & $\begin{array}{c}\text { Reference value or } \\
\text { characteristic }\end{array}$ \\
\hline Phantom material & Water \\
\hline Phantom size & $\begin{array}{l}(30 \times 30 \times 30) \mathrm{cm}^{3} \\
\text { approximately }\end{array}$ \\
\hline $\begin{array}{l}\text { Source-chamber } \\
\text { distance }^{\text {a }}\end{array}$ & $100.0 \mathrm{~cm}$ \\
\hline Air temperature ${ }^{b}$ & $20^{\circ} \mathrm{C}^{\mathrm{C}}$ \\
\hline Air pressure & $101.325 \mathrm{kPa}$ \\
\hline $\begin{array}{l}\text { Reference point of the } \\
\text { IC }\end{array}$ & $\begin{array}{l}\text { For cylindrical } \\
\text { chambers, on the } \\
\text { chamber axis at the } \\
\text { centre of the cavity } \\
\text { volume; for plane- } \\
\text { parallel chambers in } \\
\text { the inner surface of } \\
\text { the entrance window, } \\
\text { at the centre of the } \\
\text { window }\end{array}$ \\
\hline $\begin{array}{l}\text { Depth in phantom of } \\
\text { the reference point of } \\
\text { the chamber }{ }^{a}\end{array}$ & 5 g.cm ${ }^{-2}$ \\
\hline $\begin{array}{l}\text { Field size at the } \\
\text { position of the } \\
\text { reference point of the } \\
\text { chamber }\end{array}$ & $(10 \times 10)$ \\
\hline Relative humidity & $50 \%$ \\
\hline $\begin{array}{l}\text { Polarize voltage and } \\
\text { polarity }\end{array}$ & $\begin{array}{l}\text { No reference values } \\
\text { are recommended but } \\
\text { the values used } \\
\text { should be stated in the } \\
\text { calibration certificate }\end{array}$ \\
\hline Dose rate & $\begin{array}{l}\text { No reference values } \\
\text { are recommended but } \\
\text { the dose rate used } \\
\text { should always be } \\
\text { stated in the } \\
\text { calibration certificate. } \\
\text { It should also be } \\
\text { stated whether a } \\
\text { recombination } \\
\text { correction has or not } \\
\text { has been applied and } \\
\text { if so, the value should } \\
\text { be stated. }\end{array}$ \\
\hline \multicolumn{2}{|c|}{$\begin{array}{l}\text { After a water phantom with a plastic window has been } \\
\text { filled, its dimensions may slowly change with time. } \\
\text { When using a horizontal beam, it may therefore be } \\
\text { necessary to check the source-surface distance and the } \\
\text { chamber depth every few hours. } \\
\text { b The temperature of the air in a chamber cavity should } \\
\text { be taken to be that of the phantom, which should be } \\
\text { measured; this is not necessarily the same as the } \\
\text { temperature of the surrounding air } \\
{ }^{c} \text { In some countries the reference air temperature is } 22^{\circ} \mathrm{C} \text {. }\end{array}$} \\
\hline
\end{tabular}

At the hospital, before the measurements are made, this is necessary to wait the stability of the dosimetry system, when it achieves thermal stability. Some corrections are necessary because the calibration factor of an IC is valid only for the reference conditions.

The first correction is for pressure, temperature and relative air humidity [8]:

$$
k_{T, p}=\frac{(273.15+T)}{\left(273.15+T_{0}\right)} \times \frac{P_{0}}{P}
$$

In equation (4) $P$ and $T$ are the cavity air pressure and the temperature at the time of the measurements respectively, while $P_{0}$ and $T_{0}$ are the reference values (usually $101.325 \mathrm{kPa}$ and $20{ }^{\circ} \mathrm{C}$ ). If the calibration factor was referred to a relative humidity of $50 \%$ and the relative humidity at the hospital in time of measurement is between $20 \%$ and $80 \%$, no corrections for relative air humidity are needed.

The second correction depends on the calibration of the dosimetry system. If the IC and the electrometer were calibrated separately it is necessary to use the influence quantity $k_{\text {elec }}$ given by the calibration laboratory. If they were calibrated together this is not necessary.

The third correction is the polarity effect. The reading must be the mean of the absolute values of readings taken at both polarities of the electrometer. This can be accounted for by using the following correction factor [8]:

$$
k_{p o l}=\frac{\left|M_{+}\right|+\left|M_{-}\right|}{2 M}
$$

In equation (5) $M_{+}$and $M_{-}$are the electrometer readings obtained at positive and negative polarity respectively while $M$ is the electrometer reading obtained with the polarity used routinely.

The fourth correction comes from the incomplete collection of charge in an IC cavity due to the recombination of ions. This is named ion recombination. The recombination correction factor $k_{s}$ at the normal operating voltage $V_{1}$ is obtained from [8]:

$$
k_{s}=a_{o}+a_{1}\left(\frac{M_{1}}{M_{2}}\right)+a_{2}\left(\frac{M_{1}}{M_{2}}\right)^{2}
$$

In equation (6) the constants $a_{i}$ can be obtained in Table 4.VII of IAEA TRS-398 for pulsed and pulsed-scanned radiation.

\section{Methodology}

In this work the following equipments were used:

- a Varian Medical Systems CLINAC 600C/D with nominal acceleration potential of $6 \mathrm{MV}$ and beam quality $\left(T P R_{20,10}\right)$ equal to 0.657 ;

- a source-surface distance set-up with reference distance of $100.0 \mathrm{~cm}$;

- field sizes of $(5 \times 5) \mathrm{cm}^{2},(10 \times 10) \mathrm{cm}^{2}$ and $(20 \times 20)$ $\mathrm{cm}^{2}$; 
- a Wellhöffer IC 70 Farmer ionization chamber with a graphite chamber wall, thickness 0.068 g.cm ${ }^{-2}$, waterproof;

- an electrometer CNMC 1100;

- a water phantom with dimensions $(40 \times 40 \times 40) \mathrm{cm}^{3}$.

Following the instructions from TRS-398 the measurements were made respecting all the corrections for influence quantities: relative air humidity, temperature, pressure, polarity and ion recombination.

In radiation therapy the field size $(10 \times 10) \mathrm{cm}^{2}$ is used like a standard to most of measurements. The bigger the field size the bigger the scattering. There is a factor that represents the total scattering (collimators and patient). According to Khan (1994) this factor is [10]:

- less than 1 for fields small than $(10 \times 10) \mathrm{cm}^{2}$;

- equal 1 for this field size;

- greater than 1 for fields bigger than $(10 \times 10) \mathrm{cm}^{2}$.

TABLE 2: Variations in absorbed dose when the LINAC dose rate is changed from $100 \mathrm{cGy} \cdot \mathrm{min}^{-1}$ to $600 \mathrm{cGy} \cdot \mathrm{min}^{-1}$.

\begin{tabular}{cccc} 
Field size (cm & \multicolumn{3}{c}{ Depth $\mathbf{( c m )}$} \\
& $\mathbf{1 . 5}$ & $\mathbf{5 . 0}$ & $\mathbf{1 5 . 0}$ \\
$\mathbf{5} \times \mathbf{5}$ & $0.85 \%$ & $0.91 \%$ & $1.30 \%$ \\
$\mathbf{1 0} \mathbf{1 0}$ & $1.08 \%$ & $0.95 \%$ & $1.04 \%$ \\
$\mathbf{1 5} \times \mathbf{1 5}$ & $1.07 \%$ & $0.77 \%$ & $1.12 \%$ \\
\hline
\end{tabular}

As we can see the change in the Varian CLINAC 600C/D dose rate from the minimal value to the maximal value can modify the absorbed dose in about $1 \%$ with the three field sizes used in this work. This value is very small but considering the suggestion of ICRU $( \pm 5 \%)$ to the uncertainty on dose measurement this can represent about $20 \%$ of this value. The physical calculations must consider great changes in dose rate but with small changes this can be ignored.

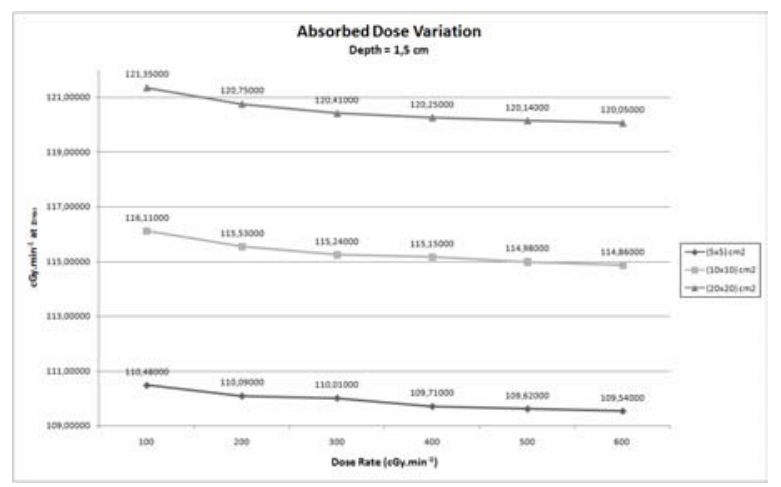

FIG. 1: Absorbed dose variation at depth $=1.5 \mathrm{~cm}$

The experiments show also that the change in dose rate in the range of lower rates is more pronounced than in higher

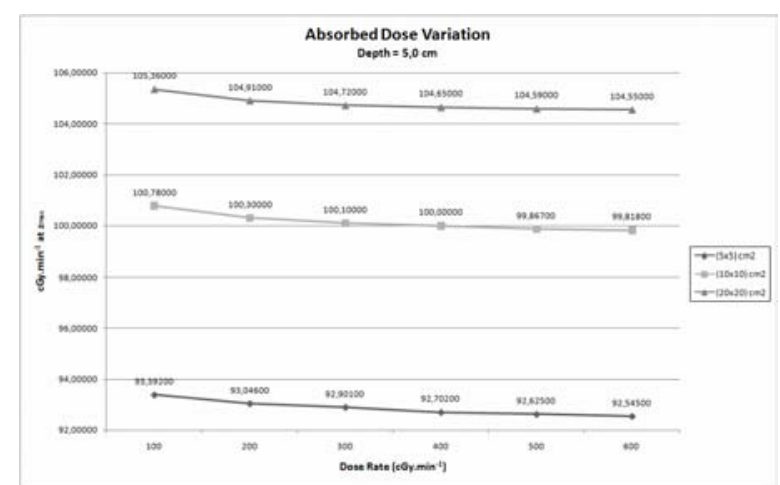

FIG. 2: Absorbed dose variation at depth $=5.0 \mathrm{~cm}$

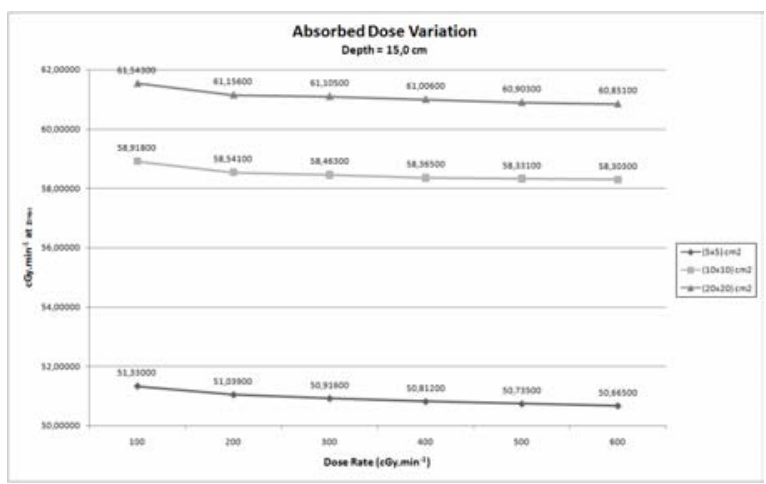

FIG. 3: Absorbed dose variation at depth $=15.0 \mathrm{~cm}$

rates. For example, when we change the dose rate from 100 cGy.min ${ }^{-1}$ to $200 \mathrm{cGy} \cdot \mathrm{min}^{-1}$, the difference in dose can be in the order of $0.6 \%$. Otherwise, when we change the dose rate from $500 \mathrm{cGy} \cdot \mathrm{min}^{-1}$ to $600 \mathrm{cGy} \cdot \mathrm{min}^{-1}$, the difference in dose is about $0.1 \%$.

\section{Results}

The following figures show the differences in deep dose deposition for 3 field sizes when we change the dose rate in the LINAC, from $100 \mathrm{cGy} \cdot \mathrm{min}^{-1}$ to $600 \mathrm{cGy} \cdot \mathrm{min}^{-1}$, irradiating $100 \mathrm{MU}$.

The measurements were made with the following environmental conditions:

- Temperature: $22^{\circ} \mathrm{C}$;

- Pressure: $92.4 \mathrm{kPa}$;

- Relative air humidity: $53 \%$.

\section{Acknowledgments}

Thanks to Hospital São João de Deus Radiation Therapy Service at Divinópolis-MG, Brazil, where the measurements were made. 
[1] Podgorsak E B. Review of radiation oncology physics: a handbook for teachers and students. Education Report Series. International Atomic Energy Agency. Vienna, Austria, 2003.

[2] IAEA. Review of radiation oncology physics: a handbook for teachers and students. Educational Report Series. International Atomic Energy Agency. Vienna, Austria, 2003.

[3] Cheng, P.; Kubo, H. Unexpectedly large dose rate dependent output from a linear accelerator. Medical Physics, 15, (5), 1988.

[4] Leenhouts H P and Chadwick K H. The influence of dose rate on the dose-effect relationship. J. Radiol. Prot. 1990 Vol. 10, $\mathrm{N}^{\circ} 2$ 95-102.

[5] Teh Lin, Yah Chen, Murshed Hossain, Jinsheng Li and C.-M. Ma. Dosimetric investigation of high dose rate, gated IMRT. Medical Physics, 35, (11), 2008.
[6] Varian Medical Systems, Inc. Low Energy C-Series CLINAC. Systems Manual. P/N 01102658-01 3/96. USA, 1996.

[7] Varian Medical Systems, Inc. C-Series CLINAC Clinical User Guide. Delivery Systems. P/N 1102903-03 7/99. USA, 1999.

[8] ICRU. Determination of absorbed dose in a patient irradiated by beams of $\times$ or gamma rays in radiotherapy procedures. Internationa Commission on Radiation Units and Measurements. ICRU Report 24, Bethesda, 1976.

[9] IAEA. Absorbed dose determination in external beam radiotherapy: an international code of practice for dosimetry based on standards of absorbed dose to water. IAEA TRS-398. International Atomic Energy Agency. Vienna, Austria, 2000.

[10] F.M. Khan, The physics of radiation therapy. Second Edition. Williams \& Wilins, USA, 1994. 